\title{
Exigência de metionina + cistina para alevinos de Tilápia do Nilo (Oreochromis niloticus)
}

\author{
Digestible methionine + cystine requirement for Nile Tilapia (Oreochromis niloticus), fingerlings
}

\author{
Wilson Massamitu Furuya ${ }^{1}$ Lilian Carolina Rosa Silva ${ }^{2}$ Patrícia Ribeiro Neves ${ }^{2}$ Daniele Botaro \\ Carmino Hayashi ${ }^{3}$ Eduardo Shiguero Sakaguti ${ }^{1}$ Valéria Rossetto Barriviera Furuya ${ }^{1}$
}

\section{RESUMO}

\begin{abstract}
Este estudo foi realizado para determinar a exigência de metionina + cistina para alevinos de tilápia do Nilo $(2,61$ $\pm 0,14 \mathrm{~g}$ ). Foi utilizado o modelo em blocos ao acaso, com seis tratamentos, três repetições e cinco peixes por unidade experimental. Foi utilizada ração basal contendo $28 \%$ de proteína bruta e $3173 \mathrm{kcal}_{\mathrm{ED} \mathrm{kg}} \mathrm{kg}^{-1}$ de ração, suplementada com $\mathrm{DL}$ metionina, resultando em rações com 0,$87 ; 0,95 ; 1,03 ; 1,11$; 1,19 e 1,27\% de metionina + cistina. As rações foram fornecidas à vontade durante 41 dias. Não foram observados efeitos $(P>0,05)$ dos níveis de metionina + cistina sobre a taxa de sobrevivência e índice hepato-somático. Foi observado efeito quadrático $(P<0,05)$ sobre o ganho de peso, que aumentou até o nível de $1,22 \%$ de metionina + cistina na ração. A conversão alimentar e a taxa de eficiência protéica aumentaram $(P<0,05)$ até o nível de $1.00 \%$ de metionina + cistina. Foi observado efeito quadrático $(P<0,05)$ sobre o rendimento de carcaça que aumentou até o nível de $1,13 \%$ de metionina + cistina. O nível de $1,00 \%$ de metionina + cistina, correspondente a 3,54\% da proteína bruta, contendo $0,54 \%$ de metionina na ração, mostrou melhor resultado no desempenho.
\end{abstract}

Palavras-chave: desempenho, exigência, juvenil, tilápia do Nilo, metionina + cistina.

\section{ABSTRACT}

This study was carried out to determine the methionine + cystine requirement for Nile tilápia, fingerlings $(2.61 \pm 0.14 \mathrm{~g})$. A randomized block designs, with six treatments, three replicates and five fish by experimental unit was used. Basal diet was utilized with $28 \%$ crude protein and $3173 D E$ $\mathrm{kcal} \mathrm{kg}^{-1}$ of digestible energy, supplemented with DL-methionine, resulting in diets with $0.87 ; 0.95 ; 1.03 ; 1.11 ; 1.19$ and $1.27 \%$ of methionine + cystine. Diets were fed to satiation during 41 days. No effects $(P>0.05)$ of methionine + cystine levels on survival rate and hepatosomatic index were observed. A quadratic effect $(P<0.05)$ for weight gain was observed, which increased up to $1.22 \%$ methionine + cystine in the diet. Feed conversion ratio and protein efficiency ratio increased $(P<0.05)$ up to $1.00 \%$ of methionine + cystine. A quadratic effect $(P<0.05)$ of methionine + cystine level on carcass yield was observed, which increased up to $1.13 \%$ of methionine + cystine. The concentration of $1.00 \%$ methionine + cystine corresponding to $3.54 \%$ crude protein, in the presence of $0.54 \%$ methionine in the diet, showed the best njperformance.

Key words: performance, requirement, juvenile, methionine + cystine, Nile tilapia.

\section{INTRODUÇÃO}

A criação da tilápia do Nilo (Oreochromis niloticus) se encontra difundida em diversos países de clima tropical e subtropical. É uma das espécies mais promissoras para a piscicultura, apresentando bom desempenho em criações intensivas, além de possuir carne com boas características organolépticas e filé sem espinhos intramusculares em forma de "Y”"(HILDSORF, 1995).

Na natureza, os peixes conseguem satisfazer suas necessidades com o alimento disponível no meio aquático. Quando confinados, devem receber ração balanceada para que sejam atendidas as suas exigências e, dessa forma, possam expressar seu potencial genético.

A farinha de peixe é a fonte protéica de origem vegetal mais utilizada em rações para peixes, pois esta se apresenta como boa fonte de energia, aminoácidos, ácidos graxos essenciais, minerais e vitaminas (PEZZATO, 1997). No entanto, os estoques de peixes utilizados para a produção de farinha de peixe mantiveram-se praticamente constantes nos últimos anos (FAO, 1998).

${ }^{1}$ Professor, Departamento de Zootecnia, Universidade Estadual de Maringá (UEM), Av. Colombo, 5790, 87020-900, Maringá, PR. E-mail: wmfuruya@uem.br

${ }^{2}$ Alunos do Curso de Graduação em Zootecnia, UEM, lilianzoo@hotmail.com, Maringá, PR.

${ }^{3}$ Professor, Doutor, Departamento de Biologia, UEM. E-mail:chayashi@uem.br 
Entre os ingredientes de origem vegetal, o farelo de soja é a fonte mais utilizada para a elaboração de rações para organismos aquáticos, pelo baixo custo e elevado valor nutricional. Esse ingrediente possui baixos teores de aminoácidos sulfurados, tornando necessária a suplementação com aminoácidos sintéticos.

De acordo com o NRC (1993), em rações para peixes onívoros, os aminoácidos sulfurados devem estar presentes na proporção de 3\% da proteína da ração. KIM et al. (1992) estimaram o valor de 0,80\% de metionina + cistina (2,3\% da proteína bruta), com $0,52 \%$ de metionina, em rações para a truta arco-íris (Oncorhynchus mykiss). TWIBELL et al. (2000) encontraram valor de $0,85 \%$ de metionina + cistina (2,50\% da proteína da ração), para juvenis de perca amarela (Perca flavescens). Valor superior de inclusão de metionina na ração foi encontrado por ALAM et al. (2001) para o flounder japonês (Paralichthys olivaceus), de 1,43\% na ração (2,8\% da proteína da ração).

Em estudo realizado com o bagre do canal (Ictalurus punctatus), BURTLE \& CAI (1995) encontraram melhor desempenho dos peixes alimentados com ração contendo 1,34\% de metionina + cistina (4,9\% da proteína bruta). Para a carpa comum (Cyprinus carpio L.), SCHWARZ et al. (1998) estimaram valor de 1,28\% de metionina + cistina, correspondente a 3,18\% da proteína bruta. Além disso, segundo esses últimos autores, 0,86\% dos aminoácidos sulfurados totais deve ser constituído por metionina.

JACKSON \& CAPPER (1982), em estudo realizado com alevinos de tilápia mossambica (Oreochromis mossambicus), obtiveram melhores resultados de desempenho com a ração contendo 1,1\% de metionina + cistina. SANTIAGO \& LOVELL (1988) determinaram a exigência de $0,95 \%$ de metionina + cistina para a tilápia do Nilo na fase inicial, utilizando rações purificadas. Resultado semelhante foi encontrado por FURUYA et al. (2001a), para essa mesma espécie e fase utilizando rações práticas, quando estimaram a exigência de $0,83 \%$ de aminoácidos sulfurados digestíveis (3\% da proteína bruta).

Poucas são as informações sobre as exigências de aminoácidos sulfurados para as tilápias. A determinação de suas exigências é importante em rações práticas, principalmente quando o farelo de soja é a principal fonte de proteína, para permitir a máxima retenção da proteína e, conseqüentemente, aumento na produtividade e redução no custo com alimentação.

O presente trabalho foi realizado com o objetivo de determinar a exigência de metionina + cistina para alevinos de tilápia do Nilo (Oreochromis niloticus), através do desempenho produtivo com ra- ções contendo diferentes concentrações destes aminoácidos.

\section{MATERIAL E MÉTODOS}

O presente estudo foi realizado no Laboratório de Aqüicultura da Universidade Estadual de Maringá, no período de 16 de setembro a 27 de outubro de 2001.

Foram utilizados 90 alevinos revertidos de tilápia do Nilo, com peso vivo inicial médio de 2,61 \pm 0,14g, originados da Piscicultura Araucária Belmonte, Rolândia - PR, distribuídos em 18 tanques-rede com volume unitário útil de $0,13 \mathrm{~m}^{3}$, em um delineamento em blocos casualizados, distribuídos de forma que cada bloco, constituído por um tanque de 1000 L, continha todos os tratamentos. Em cada tanque, foi mantido um sistema individual de renovação da água (5\% dia $\left.{ }^{-1}\right)$, aeração constante através de pedra porosa acoplada a um soprador central, sendo cobertos com tela sombrite (70\%), para minimizar a produção primária.

A ração basal foi elaborada com base na proteína do farelo de soja e formulada baseada nos valores de aminoácidos digestíveis determinados para a tilápia do Nilo por FURUYA et al. (2001b). Foi utilizada metionina cristalina na forma de DL-metionina 99\%, suplementada na proporção de 0,0; 0,8; 1,6; 2,4; 3,2 e $4,0 \mathrm{~g} \mathrm{~kg}^{-1}$ de ração, possibilitando a obtenção de rações com 0,$87 ; 0,95 ; 1,03 ; 1,11 ; 1,19$ e 1,27\% de metionina + cistina (Tabela 1). O aminoácido cristalino foi suplementado em cada ração em substituição ao milho da ração basal.

As rações foram peletizadas em prensa manual e, em seguida, desidratadas em estufa de ventilação forçada $\left(50^{\circ} \mathrm{C}\right)$ por $12 \mathrm{~h}$. Após, as mesmas foram desintegradas, selecionando os grânulos com diâmetro de $0,6 \mathrm{~mm}$ ( $1^{\circ}$ ao $\left.14^{\circ} \mathrm{dia}\right) ; 1,18 \mathrm{~mm}\left(15^{\circ}\right.$ ao $\left.32^{\circ} \mathrm{dia}\right)$ e 2,00mm ( $33^{\circ}$ ao $41^{\circ} \mathrm{dia}$ ), conforme recomendado por JAUNCEY \& ROSS (1982) para as tilápias. O arraçoamento foi à vontade até consumo voluntário, parcelado em quatro vezes (8; 12; 14 e 18h).

Todos os peixes foram pesados no início e final do experimento. Ao final do experimento, três peixes de cada unidade experimental foram utilizados para determinar o rendimento de carcaça e o índice hepatosomático. A taxa de eficiência protéica foi calculada de acordo com a expressão descrita por JAUNCEY \& ROSS (1982).

A temperatura da água foi medida diariamente (8 e 17h), enquanto os parâmetros de oxigênio dissolvido $\left(\mathrm{mg} \mathrm{L}^{-1}\right)$, $\mathrm{pH}$ e a condutividade elétrica $\left(\mathrm{mSm} \mathrm{cm}^{-1}\right)$ da água foram medidos a cada sete dias. Estes dados foram obtidos através de equipamento digital portátil. 
Tabela 1 - Composição percentual e valores calculados da ração basal

\begin{tabular}{lc}
\hline \multicolumn{1}{c}{ Ingrediente } & $\%$ \\
\hline Milho & 35,03 \\
Farelo de soja & 46,00 \\
Farelo de trigo & 8,00 \\
Farinha de peixe & 5,00 \\
Fosfato bicálcico & 1,70 \\
Óleo de soja & 3,00 \\
L-treonina $_{\text {Supl. Min. e vitamínico }}{ }^{2}$ & 0,10 \\
Vitamina C $^{2}$ & 0,50 \\
Sal comum $^{3}$ & 0,05 \\
BHT $^{3}$ & 0,50 \\
Aglutinante $^{4}$ & 0,02 \\
Total & 0,10 \\
\hline
\end{tabular}

Composição determinada (base na matéria natural)

\begin{tabular}{|c|c|}
\hline Matéria seca $(\%)^{5}$ & 89,42 \\
\hline Energia digestível (kcal/kg) ${ }^{6}$ & 3172,87 \\
\hline Proteína bruta $(\%)^{5}$ & 28,26 \\
\hline Proteína Digestível(\%) ${ }^{6}$ & 25,74 \\
\hline Fibra bruta $(\%)^{5}$ & 4,29 \\
\hline Extrato etéreo $(\%)^{5}$ & 5,84 \\
\hline Cálcio (\%) ${ }^{5}$ & 0,98 \\
\hline Fósforo total ${ }^{5}$ & 0,91 \\
\hline Fósforo disponível (\%) ${ }^{6}$ & 0,53 \\
\hline Metionina $(\%)^{7}$ & 0,40 \\
\hline Metionina + cistina $(\%)^{7}$ & 0,87 \\
\hline$\overline{\text { Lisina }(\%)^{7}}$ & 1,58 \\
\hline
\end{tabular}

${ }^{1}$ Suplemento mineral e vitamínico (Supremais): composição por kg: Vit. A = 1200.000 UI; vit. D3 = 200.000 UI; vit. $E=12.000$ mg; vit. K3 = $2.400 \mathrm{mg}$; vit. $\mathrm{B} 1=4.800 \mathrm{mg}$; vit. $\mathrm{B} 2=4.800 \mathrm{mg}$; vit. B6 = $4.000 \mathrm{mg}$; vit. B12 = $4.800 \mathrm{mg}$; ác. fólico = $1.200 \mathrm{mg}$; pantotenato de $\mathrm{Ca}=12.000 \mathrm{mg}$; vitamina $\mathrm{C}=48.000 \mathrm{mg}$; biotina $=48 \mathrm{mg}$; colina = $65.000 \mathrm{mg}$; niacina $=24.000 \mathrm{mg} ; \mathrm{Fe}=10.000$ mg; $\mathrm{Cu}=600$ mg; $\mathrm{Mg}=4.000$ mg; $\mathrm{Zn}=6.000$ mg; I = 20 mg; $\mathrm{Co}=2 \mathrm{mg}$ e $\mathrm{Se}=20 \mathrm{mg}$;

${ }^{2}$ Vitamina C: sal cálcica 2-monofosfato de ácido ascórbico com (42\% de vitamina $\mathrm{C}$ ).

${ }^{3}$ Butil Hidroxi Tolueno.

${ }^{4}$ Alginato.

${ }^{5}$ Valores determinados no Laboratório de Analise de Alimentos da Universidade Estadual de Maringá.

${ }^{6}$ De acordo com valores determinados por FURUYA et al. (2001c), para a tilápia do Nilo.

${ }^{7}$ Valores determinados no Laboratório de Alta Tecnologia, Campinas-SP.

As análises de matéria seca, proteína bruta, fibra bruta, cálcio e fósforo das rações e carcaças foram realizadas no Laboratório de Análise de Alimentos do Departamento de Zootecnia da Universidade Estadual de Maringá de acordo com as metodologias descritas por SILVA (1990). A análise dos aminoácidos foi realizada por cromatografia de troca iônica, no Laboratório de Alta Tecnologia de Campinas-SP.
Os dados foram submetidos às análises de variância e regressão polinomial, por intermédio do programa SAEG (Sistemas de Análises Estatísticas e Genéticas) (EUCLYDES, 1983).

\section{RESULTADOS E DISCUSSÃO}

Foram obtidos valores médios para a temperatura, oxigênio dissolvido, $\mathrm{pH}$ e condutividade elétrica da água dos tanques-rede de $24,5 \pm 0,48^{\circ} \mathrm{C}$; $5,70 \pm 0,17 \mathrm{mg} \mathrm{L}^{-1} ; 7,37 \pm 0,57 ; 553 \pm 32,09 \mathrm{mS} \mathrm{cm}^{-1}$, respectivamente. Os dados obtidos se encontram dentro da faixa recomendada por POPMA \& GREEN (1990) para peixes tropicais de água doce.

Na tabela 2, encontram-se os valores médios dos resultados das variáveis de desempenho dos juvenis de tilápia do Nilo, em função dos teores de metionina + cistina nas rações.

Os teores crescentes de metionina + cistina nas rações não influenciaram $(\mathrm{P}>0,05)$ a taxa de sobrevivência e o índice hepato-somático. Com o aumento na suplementação de aminoácidos sulfurados, foi observado efeito quadrático $(\mathrm{P}<0,05)$ sobre o ganho de peso (Figura 1), sendo estimado o valor de 1,22\% (1,20\% de metionina + cistina), correspondendo a 4,32\% de metionina + cistina em relação à proteína bruta como o valor que proporcionou o maior ganho de peso.

A exigência de metionina + cistina estimada nesta pesquisa se aproxima do valor obtido por JACKSON \& CAPPER (1982), quando determinaram a exigência de $1,27 \%$ de metionina + cistina para a tilápia mossambica e sugeriram o valor mínimo de metionina de $0,53 \%$, com a relação metionina + cistina/lisina de $78 \%$. Entretanto é superior ao determinado por SANTIAGO \& LOVELL (1988) e por FURUYAet al. (2001a) para alevinos de tilápia do Nilo, que recomendaram 0,90 e 0,95\% de metionina + cistina, respectivamente.

No presente estudo, o valor obtido para esta variável foi inferior ao descrito por ALAM et al. 2001, em trabalho realizado com "flounder" japonês, de 2,03\% de aminoácidos sulfurados na ração. Valores superiores ao encontrado no presente estudo para ganho de peso também foram obtidos por BURTLE \& CAI (1995) e SCHWARZ et al. (1998), em trabalhos realizados com o bagre do canal e carpa comum que estimaram valores de $1,34 \%$ de metionina + cistina (4,9\% da proteína bruta e $0,94 \%$ de metionina) e 1,28\% de metionina + cistina (3,18\% da proteína bruta e 0,86\% de metionina), respectivamente.

Para a conversão alimentar, foi observado efeito quadrático $(\mathrm{P}<0,05)$ dos níveis de metionina + cistina da ração, sendo o valor estimado em 1,00\% de metionina + cistina (3,54\% da proteína bruta) para se 
Tabela 2 - Desempenho de juvenis de tilápia do Nilo alimentados com dietas contendo valores crescentes de metionina + cistina

\begin{tabular}{|c|c|c|c|c|c|c|c|}
\hline \multirow[t]{2}{*}{ Variável } & \multicolumn{6}{|c|}{ Metionina + cistina (\%) } & \multirow[b]{2}{*}{$\mathrm{CV}^{1}$} \\
\hline & 0,87 & 0,95 & 1,03 & 1,11 & 1,19 & 1,27 & \\
\hline Peso inicial (g) & 2,70 & 2,64 & 2,53 & 2,86 & 2,44 & 2,51 & 5,34 \\
\hline Peso final (g) & 19,76 & 21,06 & 21,06 & 23,29 & 24,42 & 22,37 & 7,06 \\
\hline Ganho de peso $(\mathrm{g})^{2}$ & 17,06 & 18,42 & 18,53 & 20,43 & 21,98 & 19,86 & 8,19 \\
\hline Conversão alimentar ${ }^{2}$ & 1,10 & 1,07 & 1,14 & 1,13 & 1,01 & 1,03 & 2,40 \\
\hline Taxa de eficiência protéica ${ }^{2}$ & 3,25 & 3,34 & 3,13 & 3,16 & 3,53 & 3,47 & 6,77 \\
\hline Índice hepato-somático & 0,36 & 0,40 & 0,43 & 0,44 & 0,44 & 0,46 & 37,89 \\
\hline Sobrevivência (\%) & 80,00 & 86,67 & 80,00 & 93,33 & 60,00 & 73,33 & 10,48 \\
\hline Rendimento de carcaça ${ }^{2}(\%)$ & 84,08 & 84,74 & 85,11 & 85,19 & 84,74 & 84,68 & 1,99 \\
\hline
\end{tabular}

${ }^{1}$ Coeficiente de variação

${ }^{2}$ Efeito quadrático $(\mathrm{P}<0,05)$ : ganho de peso $\left(\mathrm{Y}=-27,357+78,9994 \mathrm{X}-32,4794 \mathrm{X}^{2} ; \mathrm{R}^{2}=0,77\right)$; conversão alimentar $(\mathrm{Y}=-0,3164+2,8523 \mathrm{X}$ $\left.-1,4231 X^{2} ; R^{2}=0,62\right)$; taxa de eficiência protéica $\left(Y=7,5975-8,7679 X+4,3808 X^{2} ; R^{2}=0,69\right)$; rendimento de carcaça $(Y=61,3873+$ $\left.43,2250 X-19,1974 X^{2} ; R^{2}=0,90\right)$

obter o melhor valor dessa variável. Para eficiência alimentar, KIM et al. (1992), em estudo com truta arco-íris, estimaram exigência de $0,68 \%$ de metionina + cistina (1,94\% da proteína bruta e $0,40 \%$ de metionina). Por outro lado, BURTLE \& CAI (1995), em pesquisa realizada com o bagre do canal, encontraram exigências de 1,40\% de metionina + cistina (5,07\% da proteína bruta e $1,00 \%$ de metionina), sendo igual ao encontrado para juvenis de perca amarela por TWIBELL et al. (2000), de 1,00\% de metionina + cistina (2,98\% da proteína da ração) para melhor conversão alimentar.

Foi observado efeito quadrático $(\mathrm{P}<0,05)$ dos níveis de metionina + cistina sobre a taxa de eficiência protéica, onde a menor taxa foi obtida com o nível de 1,00\% de aminoácidos sulfurados. Valor inferior ao obtido neste estudo para taxa de eficiência protéica foi estimado por KIM et al. (1992), em estudo com a truta arco-íris, que determinaram exigência de 0,78\% de metionina + cistina (2,23\% da proteína bruta). Em pesquisa realizada com o bagre do canal, BURTLE \& CAI (1995) estimaram valor próximo ao encontrado neste

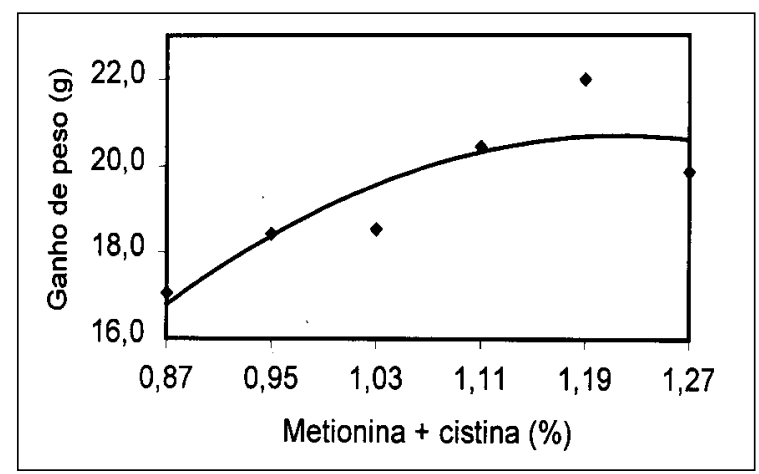

Figura 1- Ganho de peso de juvenis de tilápia do Nilo alimentados com rações contendo teores crescentes de metionina + cistina estudo, de 0,99\% de metionina + cistina (3,59\% da proteína bruta e $0,58 \%$ de metionina) na ração.

Foi observado efeito quadrático $(\mathrm{P}<0,05)$ dos teores de aminoácidos sulfurados digestíveis da ração sobre o rendimento de carcaça, em que foi estimado o valor de 1,13\% (4,00\% da proteína bruta) para o máximo valor dessa variável (Figura 2). O maior rendimento de carcaça pode estar relacionado com o aumento de proteína corporal, assim como obtido por BURTLE \& CAI (1995), que obtiveram maior conteúdo de proteína corporal com $1,17 \%$ de metionina + cistina (4,25\% da proteína bruta e $0,77 \%$ de metionina), para alevinos de bagre do canal.

Considerando as variáveis de ganho de peso, conversão alimentar, taxa de eficiência protéica e de rendimento de carcaça, nas rações com os teores mais elevados de inclusão de metionina cristalina (3,2 e 4,0g $\mathrm{kg}^{-1}$ de ração), foi

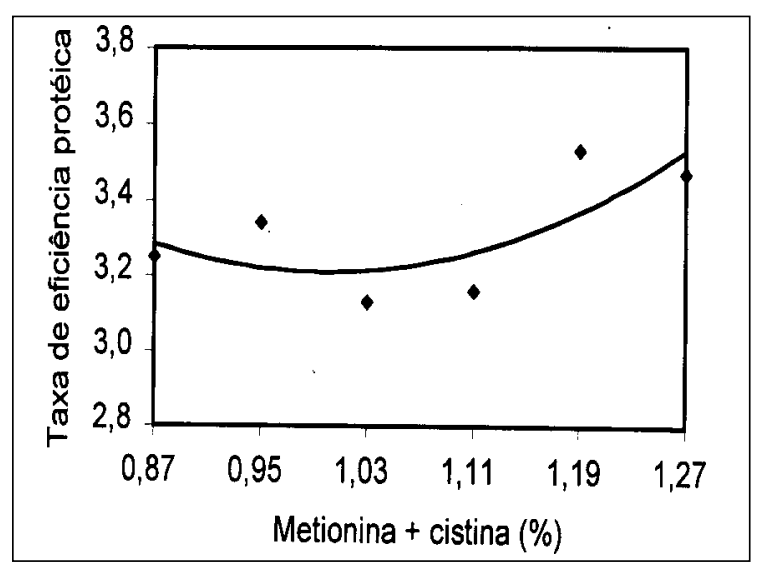

Figura 2- Rendimento de carcaça de juvenis de tilápia do Nilo alimentados com rações contendo teores crescentes de metionina + cistina 
observado redução no desempenho. Isso pode ter ocorrido pela inter-relação entre os aminoácidos e/ ou pelo seu efeito tóxico. Provavelmente, formouse um “pool” de aminoácidos incompatível com a capacidade hepática em utilizá-lo, uma vez que a metionina sintética é absorvida mais rapidamente que a metionina ligada à proteína.

Os resultados do presente estudo demonstram que a adequada suplementação de metionina em rações contendo o farelo de soja como principal fonte protéica resulta em aumento no crescimento, eficiência na utilização da proteína e rendimento de carcaça de alevinos de tilápia do Nilo.

\section{CONCLUSÕES}

Para juvenis de tilápia do Nilo (Oreochromis niloticus) a utilização de 1,00\% de metionina + cistina, correspondente a $3,54 \%$ da proteína bruta, contendo $0,54 \%$ de metionina na ração, proporciona melhores resultados de desempenho.

\section{REFERÊNCIAS BIBLIOGRÁFICAS}

ALAM, M.S. et al. Methionine requirement of juvenile japanese flounder Paralichthys olivaceus estimated by the oxidation of radioactive methionine. Aquaculture Nutrition, v.7, p.201209, 2001.

BURTLE, G.J.; CAI, Y.J. Additional methionine supplementation required in soybean meal/corn-based diets for channel catfish. UGA Animal \& Dairy Science, p.2-10, 1995.

EUCLYDES, R.F. Manual de utilização do programa SAEG (Sistema para análises estatística e genética). Viçosa : UFV, 1983. 59p.

FAO. Aquaculture production statistic 1987-1996. Rome: FAO, 1998. 197p.

FURUYA, W.M. et al. Exigências de metionina + cistina para alevinos revertidos de tilápia do Nilo (Oreochromis niloticus), baseadas no conceito de proteína ideal. In: REUNIÃO DA SOCIEDADE BRASILEIRA DE ZOOTECNIA, 2001a, Piracicaba. Anais... Piracicaba : Sociedade Brasileira de Zootecnia, 2001a. p.1418-1419.
FURUYA, W.M. et al. Coeficientes de digestibilidade e valores de aminoácidos digestíveis de alguns ingredientes pela tilápia do Nilo (Oreochromis niloticus). Revista da Sociedade Brasileira de Zootecnia, Viçosa, v.30, n.4, 2001b.

FURUYA, W.M. et al. Coeficientes de digestibilidade aparente da energia e nutrientes de alguns ingredientes pela tilápia do Nilo, Oreochromis niloticus L. (linhagem tailandesa). Acta Scientiarum, v.23, n.2, p.465-469, 2001c.

JACKSON, A.J.; CAPPER, B.S. Investigations into requirements of the tilapia (Sarotherodon mossambicus) for dietary methionine, lysine and arginine in semi-synthetic diets. Aquaculture, v.29, p.289-297, 1982.

JAUNCEY, K.; ROSS, B. A guide to tilapia feeds and feeding. Scotland : University, 1982.

HILDSORF, A.W.S. Genética e cultivo de tilápias vermelhas, uma revisão. Boletim do Instituto de Pesca, v.22, p.73-87, 1995.

KIM, K. et al. Requirements for sulfur amino acids and utilization of D-methionine by rainbow trout (Oncorhynchus mykiss). Aquaculture, v.101, p.95-103, 1992.

PEZZATO, L.E. Alimentos convencionais e não-convencionais disponíveis para a indústria da nutrição de peixes no Brasil. In: SIMPÓSIO INTERNACIONAL SOBRE NUTRIÇÃO DE PEIXES E CRUSTÁCEOS, 1997, Campinas. Anais... Campinas : CBNA, 1997. p. 34-52.

POPMA, T.J.; GREEN, B.W. Sex reversal of tilapia in earthen ponds. Aquaculture production manual. Alabama: Auburn University, Alabama Research and Development, 1990. 15p. (Series 35).

NRC. Nutrient Requirements of warmwater fishes and shellfishes. Washington : National Academy, 1993. 102p.

SILVA, S.S. Análise de alimentos (métodos químicos e biológicos). 2. ed., Viçosa: UFV. 1990. 166p.

SANTIAGO, C.B.; LOVELL, R.T. Amino acid requirements for growth of Nile tilapia. Journal of Nutrition, v.118, p.1540-1546, 1988.

SCHWARZ, F.J. et al. Studies on the methionine requirement of carp (Cyprinus carpio L.). Aquaculture, v.161, p.121129, 1998.

TWIBELL, R.G. et al. Dietary sulfur amino acid requirement of juvenile yellow perch fed the maximum cystine replacement value for methionine. Journal of Nutrition, v.130, p.612-616, 2000. 